\section{Adrenotropic Hormone (ACTH), Aminopterin and Eosinophil Count}

RECENT experiments indicate that a relationship might exist between aminopterin and adrenal cortex function. Dougherty and Dougherty ${ }^{1}$ report that, following adrenalectomy, mice do not show the lymphopænia and acute atrophy of lymphatic tissue which are observed following a lethal dose of aminopterin. Higgins ${ }^{2}$, using aminopterin and aminoteropterin, showed that adrenalectomy minimized considerably the changes induced by such drugs within the spleen, the thymus gland, the peripheral blood and bone marrow of rats. They assumed that some effects of aminopterin can be due to a stimulation of the adrenal cortex. On the other hand, Hanlon ${ }^{3}$ of the Mayo Clinic has observed that aminopterin in human subjects gives a rather marked decrease in the output of corticosteroids and, in no case, an increase.

In our experiments we first attempted to see whether administration of adrenotropic hormone (ACTH) (kindly supplied by Irby Bunding, of the Biochemical Department, Armour and Company, Chicago, Illinois) would influence the survival time of mice injected with $50 \mathrm{mgm}$. per $\mathrm{kgm}$. of aminopterin (kindly supplied by Dr. J. M. Ruegsegger, of the Lederle Laboratories Division, American Cyanamid Company, Pearl River, New York).

Twelve albino mice (mean weight $20 \mathrm{gm}$.) were divided into two groups. Each mouse of the first group was injected with $1 \mathrm{mgm}$. of aminopterin intraperitoneally and these were used as controls. The mice of the second group received $1 \mathrm{mgm}$. of aminopterin intraperitoneally and $2 \mathrm{mgm}$. of ACTH intramuscularly, divided in two doses. The ACTH was then given to them in the same dosage every day until death occurred. All the animals of both groups died within the fourth day after the injection of aminopterin. No appreciable difference was detected in the time of survival between the animals not treated with ACTH and those which received 2 mgm. of ACTH daily. In other words, in our experiments a stimulation of the adrenal cortex by ACTH does not affect the toxicity of aminopterin, although an absence of its function has been stated to minimize the effects of the aminopterin and teropterin.

Another point we tried to establish was whether aminopterin could interfere with the response of the adrenal cortex to ACTH. The response of the adrenal cortex to the stimulation by the adrenocorticotropic hormone was tested by means of an eosinophil count. The eosinophils were stained by Pilot's method ${ }^{4}$.

Experiments were performed on eight guinea pigs (mean weight $500 \mathrm{gm}$.). On each of the animals an eosinophil count was done. The following values were obtained: $116,84,90,45,160,35,214,180$. Then $1 \mathrm{mgm}$. of ACTH was given to each animal, and after four hours another eosinophil count gave the following results : $45,50,35,10,40,0,60,70$. In other words, all the animals showed a drop of eosinophils which was about one-half or more of the initial count.

Then each guinea pig received one mgm. of aminopterin intraperitoneally every day for five days. On the fifth day another eosinophil count was made on them and the following values were obtained : 45,32 , $64,0,700,40,0,400,27$. (The two guinea pigs which showed an increased eosinophil count were found at necroscopy to be pregnant at a very early stage.) Then $1 \mathrm{mgm}$. of AC'TH was given to each animal, and after four hours a new eosinophil count was made. The results were respectively: $10,0,3,0,120,0,0$, 85,0 . In other words, the animals treated with aminopterin showed a normal response (so far as it can be determined through the eosinophil count method) of the adrenal cortex to ACTH. Since the decrease of eosinophils following ACTH in animals treated with aminopterin has been more marked than in the control animals, it might be assumed that the response to ACTH is increased in animals treated previously with aminopterin. This would concur with the findings of adrenal cortex hypertrophy in animals treated with aminopterin. On the other hand, it is difficult for us to explain the observation by Hanlon ${ }^{3}$ of a decreased output of corticosteroids in patients treated with aminopterin, unless it might be caused by the difference in the dose of aminopterin.

I am grateful to Mr. Maurice Szafarowicz for technical assistance.

Sacred Heart Hospital, Pensacola, Fla.

${ }^{1}$ Dougherty, J. H., and Dougherty, T. F., J. Lab. Clin. Med., 35, 271 (1950).

${ }^{2}$ Higgins, G. M., Proc. Staff Meet. Mayo Clinic, 24, 533 (1949).

- Hanlon, D. G., Mason, H. L., and Stickney, J. M., J. Lab. and Clin. Med., 36, 877 (1950).

${ }^{4}$ Pilot, M. I., Amer. J. Clin. Path., 20, 870 (1950).

\section{Histochemical Evidence of the Presence of Acid-Phosphatase-Positive and-Negative Cell Islets in the Adrenal Medulla of the Rat}

RECENT investigations have demonstrated the presence of noradrenaline as well as adrenaline in the adrenal medulla of some mammals. In this communication, histochemical observations are reported indicating the presence of two different kinds of cell islets in the adrenal medulla of the rat.

The material consisted of about fifty adrenals of healthy rats. For the demonstration of acid phosphatase an improved technique ${ }^{1}$ modified from Gomori's ${ }^{2}$ procedure was used. This technique always gave reproducible results free of the capricious variations frequently characterizing the original method.

The greater part of the adrenal medulla contained large amounts of histochemically demonstrable acid phosphatase, already evident after immersion for $10 \mathrm{~min}$. in the substrate solution. Another part, on the contrary, was still pale in sections treated for two hours in the substrate. The accompanying

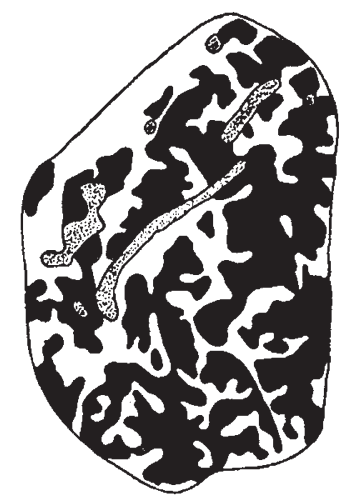

Camera lucida drawing showing the distribution of acid-phosphatase-positive materials in the adrenal medulla of a male rat 